\title{
Svetlana Kmecová
}

\section{IZRAZI ZA STRUNSKA GLASBILA V KOMPONENTNI SESTAVI SLOVAŠKIH IN SLOVENSKIH FRAZEMOV}

CoBISS: 1.01

\begin{abstract}
V prispevku obravnavamo različne konstrukcijske tipe slovaških in slovenskih frazemov, pri katerih je vsaj ena izmed sestavin poimenovanje za kordofone, torej za strunska glasbila, konkretno violina (gosli), klavir, kontrabas (bas), harfa, citre in bendžo, njihove izpeljanke in tudi nekatere lekseme, ki so z njimi pomensko povezani. Dane frazeološke in leksikalne enote analiziramo glede na nastanek, izvor, ekvivalentnost idr., pri čemer jih skušamo interpretirati z ustreznimi slovaškimi in slovenskimi civilizacijskimi dejstvi. Ključne besede: slovaška frazeologija, slovenska frazeologija, glasbeni motivi, kordofoni, frazeološka ekvivalentnost
\end{abstract}

\section{Expressions for Chordophone Instruments in Slovak and Slovenian Phrasemes}

This article describes various construction types of Slovak and Slovenian phrasemes whose component structures include names of chordophones (i.e., instruments making sound with vibrating strings; namely, the violin, piano, double bass, harp, zither, and banjo), their derivations, and some lexemes that are closely related in meaning. It then analyses the phraseological and lexical units in terms of motivation, origin, equivalence, and so on, and links them to relevant Slovak and Slovenian cultural realia.

Keywords: Slovak phraseology, Slovenian phraseology, musical motifs, chordophones, phraseological equivalence

\section{UVOD}

Glasba je podobno kot jezik reprezentativno sredstvo komunikacije, toda $\mathrm{v}$ primerjavi z jezikom ne pozna komunikacijskih ovir in njeno »govorico« razumejo vsi. S frazeologijo ima skupno izražanje specifičnih, visoko ekspresivnih vsebin. $\mathrm{Na}$ svetu do zdaj ni bilo kulture oz. oblike civilizacije, ki ne bi imela na voljo lastnega sistema jezikovnih in glasbenih izraznih sredstev (Dobríková 2014). Ker pa glasba spremlja človeka vso zgodovino, od njegovih začetkov, $\mathbf{1}$ je logično, da so se pojavi, dejanja in predmeti, povezani z glasbenimi oz. tudi plesnimi izrazi

Prispevek je nastal v okviru raziskovalnega projekta Ministrstva za šolstvo, znanost, raziskovanje in šport Slovaške republike VEGA 1/0543/14 Metaforični vokalno-inštrumentalni elementi v slovaščini in slovanskih jezikih.

1 Po podatkih so najstarejše glasbilo, 60.000 let staro piščal, ki jo je izdelal neandertalec, našli na arheološkem najdišču Divje babe v Sloveniji leta 1995 in je trenutno del zbirke Slovenskega narodnega muzeja v Ljubljani. Na Slovaškem so odkrili paleolitsko koščeno cev brez lukenj v jami Dzeravá skala blizu Plaveckega Mikuláša (Leng 1967: 96). 
človeka, odzrcalili še v jezikovni sliki sveta in prešli v jezik tudi kot sestavni del ustaljenih frazeoloških besednih in stavčnih zvez.

1.1 Slovenska ustreznica slovaškega leksema hudba je glasba in na prvi pogled gre tu za besedi z različnima etimologijama. Pri slovaškem leksemu hudba, poznanem že v praslovanščini v obliki godbba, dobesedno ,godenje“, 2 sorodnem npr. $\mathrm{z}$ besedami hudec, hudlikat', husle ipd., gre verjetno za izpeljanko od glagola húst', v praslovanščini gosti (god-ti), ki ima izvor v onomatopejskem indoevropskem korenu *gŏu-, *gouə, *gū in je povezana tudi z leksemom hovorit' (SESS 2015: 212, 214). Slovenska beseda glasba je izpeljanka leksema glas, v praslovanščini *golsz s pomenom ,glas, zvok, zvolanie“, indoevropski koren je *gal-, torej „klicati, vpiti“ (SES 1997: 142). V slovaški frazeologiji najdemo sestavino hudba npr. v zvezah hudba budúcnosti s pomenom 'kaj trenutno zelo oddaljenega, neuresničljivega' ali nebeská (rajská) hudba 'to rad slišim' (SSSJ 2011: 205). Slovenski slovarji frazema glasba prihodnosti ne navajajo, najdemo pa ga v korpusu Gigafida. Znana je tudi zveza nebeška glasba, večinoma v pomenu 'zelo lepa, prijetna glasba, zvoki', obstajajo pa tudi primeri uporabe s prenesenim pomenom, podobnim kot v slovaščini. V obeh jezikih se kot frazeološka komponenta pojavlja tudi pogovorni leksem muzika, ki je sestavni del več dvojic frazemov na visoki stopnji ekvivalentnosti, npr. to je iná muzika : to je pa druga muzika, mačacia muzika : mačja muzika, za málo peňazí málo muziky : za malo denarja malo muzike.

1.2 Najbolj razširjena in splošno priznana klasifikacija glasbenih inštrumentov avtorjev Ericha von Hornbostela in Curta Sachsa je iz leta 1914. Njena prednost je predvsem to, da je odprta in po potrebi jo je mogoče kadar koli širiti in dopolnjevati (Kurfürst 2002: 91). Glasbila so tu razdeljena v štiri skupine, pri čemer je merilo fizikalna značilnost tvorbe tonov. V prvo skupino spadajo idiofoni, to je idiofonska, samozvočna glasbila: izvor zvoka je pri njih telo glasbila, ki se razzveni z udarcem, tresenjem, s trenjem dela glasbila ipd. Sem uvrščamo dromljo, razne vrste zvonov, raglje, klepetala ipd. V naslednjo skupino lahko uvrstimo membranofona glasbila, torej glasbila z opno ali membrano, kamor spadajo različne vrste bobnov in tamburinov. Toni v njih nastajajo z vibracijo prožne membrane, ki je pripeta na resonančno telo. Pri igranju nanje ni mogoče menjati višine tonov, zato služijo kot ritmični element. Pri glasbilih tretje skupine, kordofonih, strunskih glasbilih, je za nastanek tona potreben vibrator, $v$ tem primeru struna, in resonančna omarica, $t j$. telo glasbila, strune pa lahko razzveni lok, paličica ali pa glasbenikovi prsti. Glede na to se kordofoni še naprej delijo na godala, tolkala in brenkala. V to številno skupino glasbil spadajo violina, kontrabas, kitara, klavir, cimbal, bendžo, harfa,

2 Za leksikalni pomen uporabljamo dvojne spodnje-zgornje narekovaje, za frazeološkega pa enojne zgornje. 
citre, tamburica 3 in druga. Zadnjo skupino tvorijo t. i. aerofoni, zrakovna glasbila. Ton v njih nastaja z nihanjem zraka, ki od zunaj obdaja inštrument ali pa prodira $\mathrm{v}$ cev inštrumenta. Sem spadajo dude, harmonika, različne vrste piščali, orgle, rog, trobenta itd.

1.3 V slovaškem in slovenskem frazeološkem fondu najdemo enote, kjer je ena od sestavin poimenovanje glasbil iz vseh štirih opisanih skupin. Med njimi so mnogi internacionalizmi, kot na primer hrat' prvé husle (slš.) : igrati prvo violino (sln.), 4 počut'svadobné zvony (slš.) : slišati poročne zvonove (sln.), príst' (vyjst') na bubon (slš.) : priti (iti) na boben ( $\operatorname{sln}$.) itd., druge se pojavljajo le v enem izmed raziskovanih jezikov, na primer slovaški frazem dostat' na bendžo s pomenom 'biti pretepen' ali slovenska enota Stalinove orgle (orglice), ki je med drugo svetovno vojno v vojaškem žargonu označevala sovjetski raketomet katjušo. V analiziranem korpusu frazemov najdemo tudi take, v katerih oba jezika za izražanje enakega pomena uporabljata različno glasbilo, na primer v dvojici ist's niečím na bubon (slš.) : obešati (obesiti) kaj na 〈veliki zvon (sln.). Nastanek frazemov, kjer je ena od sestavin glasbeni inštrument, je lahko motiviran na različne načine - posamezni frazemi se lahko nanašajo na funkcijo glasbenega inštrumenta, njegovo obliko, zvok in podobno. »S frazeološkega in etnomuzikološkega vidika predstavljajo omembe vredno skupino frazemov tisti, ki se nanašajo na signalno funkcijo glasbenih inštrumentov« (Dobríková 2016: 425). Gre za razmeroma obsežno skupino enot, v katerih najdemo sestavine zvon, boben, trobenta, piščalka in njihove izpeljanke, v slovaščini na primer zvonit' (trúbit', bit', bubnovat') na poplach, ist's niečim na bubon, odzvonit' niekomu, v slovenščini po toči zvoniti 〈je prepozno〉, biti plat zvona, biti na bobnu idr.

1.4 Kljub mnogim zgodovinskim, geografskim in kulturnim podobnostim med Slovaško in Slovenijo se zaradi različnih, zlasti geopolitičnih vplivov ljudski inštrumentariji obeh narodov v več pogledih razlikujejo. Poleg enakih glasbil, kot so violina, kontrabas, boben, zvon, različne piščali, trobente in rogovi, cimbal itd., opažamo tudi več regionalnih posebnosti. Dude, tipično pastirsko glasbilo, so do danes ohranile v slovaški kulturni dediščini visok status, kar je vidno tudi v več slovaških frazemih, kjer je njihovo poimenovanje sestavni del frazema, na primer šaty ako gajdy 'široka, raztegnjena oblačila', spustit' gajdy 'začeti jokati', nat'ahovat' gajdy ‘jokati’ idr. Mária Dobríková v svoji analizi slovaških in bolgarskih frazemov s

3 Tamburica, ki je prišla na Balkan v času turških vpadov v 14. in 15. stoletju, se razmeroma pogosto pojavlja kot sestavni del hrvaških frazemov in to predvsem v narečjih, npr. udarati koga po tamburi v pomenu 'tepsti koga po glavi' (gl. tudi Svítková 2015) in podobno. To glasbilo je znano tudi v Sloveniji, predvsem v obmejnih predelih s sosednjo Hrvaško. Pri zbiranju gradiva nismo izsledili nobenega slovenskega frazema s sestavino tambura, ne izključujemo pa možnosti obstoja, predvsem v narečjih.

4 Kadar ni popolnoma jasno razvidno, v katerem jeziku se frazem uporablja, v prispevku uporabljamo okrajšavi slš. za slovaščino in sln. za slovenščino. 
komponento gajdy navaja tudi slovaške leksikalne enote, izpeljane iz samostalnika gajdy: ekspresivno poimenovanje rozgajdanec ,neredno oblečen, neurejen človek“, glagol rozgajdat'sa s pomenom „,neredno se obleči, biti neurejen“ in tudi pridevnik rozgajdaný in prislov rozgajdane z identičnim pomenom glede na ustrezno morfološko obliko (Dobríková 2010: 115). Dude, ki so bile na Slovaškem tipično glasbilo ljudskih glasbenih skupin, so torej motivirale nastanek razmeroma velikega števila leksikalnih in frazeoloških enot, v Sloveniji pa se niso nikoli povsem udomačile (Kumer 1983) in so danes bolj znane iz tujega okolja. Slovaška posebnost, lahko bi rekli simbol slovaške ljudske glasbene kulture, je fujara, $\mathbf{5}$ dolg lesen aerofon s pomožno cevjo za dotok zraka in tremi luknjicami, ki izvira iz 17. stoletja (Mačák 1995: 78). Posebnost slovenskega ljudskega inštrumentarija v primerjavi s slovaškim so citre, ki so še danes priljubljen glasbeni inštrument. Kot posebnost lahko omenimo tudi trstenke, torej različne vrste ljudskega glasbila, podobnega panovi piščali. »Harmonika je danes gotovo najbolj množično igrano ali poslušano glasbilo v Sloveniji. Poleg izjemne socialne funkcije, ki jo ima v vsakdanjih ljudskih glasbenih praksah, je vključena tudi v simbolno ikonografijo predstavitve slovenstva.« (Kovačič 2015: 87) Povezana je predvsem s t. i. narodnozabavno glasbo. O tem, da so za slovenski narod tipični tudi glasbeni izrazi vokalnega značaja, priča slovenska splošnica trije Slovenci-pevski zbor (o tem tudi Kržišnik 2014).

1.5 Leksemi, ki označujejo kordofona glasbila in njihove izpeljanke, so sestavni del mnogih leksikaliziranih in terminoloških besednih zvez (na primer elektrická gitara (slš.) : električna kitara (sln.), klavírny sprievod (slš.) : klavirska spremljava (sln.), husl'ový klúč (slš.) : violinski ključ (sln.), pogosti so tudi priimki - na Slovaškem na primer Basa, Cimbal, Citara, Bendžo, v Sloveniji pa gre predvsem za izpeljanke, na primer Goslar, Citrar, Cimbaljević in podobni. Predmet raziskave našega prispevka so različni kontrukcijski tipi sintagmatskih frazemov in frazeotekstemov, ${ }^{6}$ ki v svoji sestavi vsebujejo poimenovanja kordofonih glasbil, njihove izpeljanke oz. lekseme, ki so z njimi pomensko neposredno povezani. Raziskovalno gradivo smo črpali iz slovaških in slovenskih leksikografskih in frazeografskih virov in paremioloških zbirk, navedenih v bibliografiji, omenimo pa naj tudi zbirko pregovorov Inštituta za slovensko narodopisje ZRC SAZU. Za iskanje in preverjanje enot smo uporabljali korpusa, in sicer Slovaški narodni korpus (SNK) in Gigafida. V članku uporabljamo slovaško frazeološko terminologijo.7

5 Slovenski otroci lahko o fujari izvedo npr. iz delovnega zvezka Glasba 6, namenjenega 6. razredu devetletke, kjer so našteta pihala iz raznih držav sveta. Kljub temu da gre v primeru fujare za glasbeni inštrument, ki je tipičen za slovaško ljudsko glasbo, sestavine fujara nismo našli v nobenem frazemu, pojavlja se samo v pogovorni, delno frazeologizirani slovaški besedni zvezi z značajem vzklika babkinu fujaru, ki izraža nezaupanje, negativno stališče govorečega do povedanega. frazeoleksemom, kar je frazem nominativnega in predikativnega tipa (Mlacek - Durčo 1995: 31). Zato tudi termini frazeotekstem, aktualizacija itd. (gl. Mlacek - Durčo 1995). 
1.6 Cilj prispevka ni zbrati vse frazeme, v katerih se kot sestavina pojavlja poimenovanje kordofona, ampak orisati problematiko obstoja glasbenega koncepta $\mathrm{v}$ frazeologiji, opozoriti na nekatere njegove podobnosti in razlike v slovaški in slovenski frazeologiji ter na tak način zapolniti nekatere bele lise v slovanski primerjalni frazeologiji. Istočasno želimo s prispevkom tematsko in vsebinsko razširiti znanstveno-raziskovalno usmeritev projekta Metaforični vokalno-inštrumentalni elementi v slovaščini in slovanskih jezikih, $8 \mathrm{v}$ okviru katerega se je s frazemi s področja glasbenega spektra v slovaščini in slovenščini delno ukvarjala samo Mária Dobríková (gl. Dobríková 2015; 2016).

\section{POSAMEZNI INŠTRUMENTI V KOMPONENTNI SESTAVI FRAZEMOV}

\subsection{Frazemi s sestavino husle : violina/gosli}

Violina je najbolj razširjeno godalo, ki je po dolgem in zapletenem razvoju iz stare violine da braccio dobilo dokončno podobo v drugi polovici 16. stoletja (Laborecký 1997: 99). Njena priljubljenost in razširjenost se zrcali tudi v frazeologiji, $v$ analizirani skupini frazemov jih največ vsebuje prav to sestavino. V Sloveniji je ustreznica leksema husle leksem violina, starejši izraz, katerega raba peša, je leksem gosli. 9 Najbolj znane enote so tu internacionalizmi hrat' prvé husle (slš.) s pomenom 'biti prvi, voditi v kaki dejavnosti, imeti v kolektivu odločujočo vlogo, besedo, izstopati v čem' in hrat' druhé husle (slš.), torej 'biti v kolektivu v podrejenem položaju, zaostajati za kom'. V slovenščini obstajata popolni ustreznici igrati prvo violino, igrati drugo violino, kot tudi delni ustreznici biti prva violina, biti druga violina. $\mathrm{O}$ teh frazemih se predpostavlja, da so morda nastali v nemškem okolju (Mokijenko 2014: 25). Motivirani so $\mathrm{z}$ razdelitvijo vlog $\mathrm{v}$ tradicionalnem godalnem kvartetu, ki ga tvorita dva violinista, violist in violončelist, oz. tudi v orkestru. Prvi violinist, t. i. primarius (od tega je tudi sinonimni slovaški frazem hrat' prím), igra osrednjo melodijo skladbe, najvišje tone in najhitrejše dele, drugi violinist njegovo igranje spremlja in dopolnjuje. Ti frazemi se pogosto uporabljajo v publicističnem stilu, in to na področjih, kot so politika, šport ipd. Enoto igrati prvo violino smo našli tudi kot sestavni del slovenske ljudske modrosti z zgradbo zložene povedi pamet, prežlahtna gospa, prvo naj violino igra, njej podrejene naj bodo strasti, nagone naj neurejene kroti, še čustva za svet jo sprašujejo naj, pa v hišo srca naselil se bo raj, na drugi strani pa so tudi že predniki današnjih Slovencev vedeli: hladen razum brez čustva je kakor violina brez strun (vir: zbirka pregovorov Inštituta za slovensko narodopisje ZRC SAZU, kraj Rateče).

$8 \quad$ Projekt je nastal na Oddelku za slovanske filologije Filozofske fakultete Univerze Komenskega v Bratislavi leta 2014. V njegovem okviru je potekala tudi znanstvena konferenca Glasbeni motivi v frazeologiji; prispevki z nje so bili objavljeni v istoimenskem zborniku, ki je izšel kot šesti del serije Frazeologické štúdie. Avtorji prispevkov v njem analizirajo različne vidike glasbenega koncepta $\mathrm{v}$ frazeologiji petnajstih jezikov. Zbornik je doživel tudi oceno v slovenščini (Stramljič Breznik 2015).

9 V korpusu Gigafida smo našli 13.915 zadetkov za leksem violina in 579 za gosli. 
Kljub temu da slovenski slovarji ne zajemajo ustaljene glagolske besedne zveze igrati tretjo violino, biti tretja violina oz. imenske tretja violina, več kot trideset primerov iz korpusa Gigafida priča o visoki stopnji njihove frazeologizacije. Redke niso niti aktualizacije, torej frazemi $z$ drugim vrstilnim števnikom, pri čemer velja, da čim višji števnik se uporabi, tem bolj podrejeno vlogo označevanega izraža, števnik torej stopnjuje pomen frazema, na primer:

Udarna je tudi njegova izjava, ki pove vse o krutosti kronometra, kjer je naslov branil Nemec Grabsch. »Mnogi pravijo, da sem peta violina. A sem poleg Brajkoviča edini, ki si upa svoja jajca odnesti v Švico. Ostali so nastop odpovedali.« (sln.) (Vir: Gigafida10)

Podobno se zveza hrat' tretie husle oz. tudi aktualizacija hrat' štvrté (piate) husle uporabljata tudi v slovaščini, na primer:

Európska politika hrá aj v krajinách »starej Európy«, čo sa týka atraktívnosti pre luudí, a teda mediálneho priestoru, takpovediac štvrté či piate husle. Ďaleko v Bruseli, príliš abstraktná, t’ažko sa z nej cez médiá robí niečo, čo je o životoch l’udí. (slš.) (Vir: SNK11)

Govor oz. tudi pomen povedanega, na katerega vpliva osebnost govorca, je metaforično izražen v slovaškem reku aké husle, taký zvuk, aké gajdy, taký huk oz. $\mathrm{v}$ različici aký zvon, takýzvuk, aké gajdy, taký huk. Iz nasprotij slovaških leksemov husle/zvon in gajdy/zvon je razvidno, da poleg tega izražata še nasprotje pozitivno : negativno (človek, govor, misel itd.). V slovenščini podobno miselno vsebino, toda brez intenzifikacije z opisanim nasprotjem, izražata paremiji kakršen človek (mož), taka beseda in tudi kakršna ptica, takšna pesem.

Starejša slovenska stalna besedna zveza kazati gosli izraža pomen 'imeti gol vrat in prsi'. Izhaja iz starejšega pomena leksema gosli „prsni koš““ (gl. Bezlaj 1977: 163). Sestavino gosli vsebuje tudi paremiološka enota stare gosli pojo, staro grlo pa nak (sln.). V analizirani skupini slovaških frazemov smo zabeležili tudi ekspresivni vzklik Ježiškove husličky!, s katerim govorec izraža svoje začudenje oz. razburjenje ali celo ogorčenje. Element, ki izrazito okrepi ekspresivnost frazema, je tukaj uporaba manjšalnic.

V slovenskem paremiološkem fondu smo našli več enot s pomenom 'ne splača se biti iskren, govoriti resnico', na primer kdor resnico gode, njemu gosli na glavi razbijejo; kdor resnico gode, temu gosli zbijejo; kdor resnico gode, njega z godalom tepo idr. Frazeotekstem s podobnim pomenom in obliko $k d o$ nevděčnou pánům pravdu hude, houslemi o hlavu mit bude obstaja v češčini. V slovaščini mu je pomensko najbližja enota brez sestavine husle, in sicer povedz pravdu, prebiješ hlavu.

Glagolski sestavini húst': gosti, torej ,,igrati na glasbeni inštrument (po navadi na violino)“(SSSJ 2011: 222), tukaj metaforično označujeta govorjenje, človeški govor. Tako je tudi v več slovaških frazemih, na primer húst’ niekomu poza uši (okolo uši)

$10 \mathrm{http}: / /$ www.gigafida.net/Concordance/Search?q=peta+violina

$11 \mathrm{http}: / /$ korpus.juls.savba.sk:8080/manatee.ks/do_query?query=piate\%20husle\&corpname=prim -6.0-public-all\&start $=0 \& \mathrm{cnt}=10$ 
s pomenom 'besedno koga nenehno vznemirjati, nadlegovati, utrujati' ali pa v enoti húst' si svoje, ki pomeni 'nenehno ponavljati svoje stališče, vztrajati pri svojem'. Njena ustreznica v slovenščini je zveza vedno gosti eno in isto, to pa težko opredelimo kot frazeološko. Podobno miselno vsebino 'ponavljati vedno eno in isto' izražata tudi paremiološki enoti vždy jednu nôtu hudie in vždy na jedny gajdy hudie $\mathbf{1 2}$ (slš.).

V slovenščini najdemo komponento gosti v več frazemih. Z vidika ekvivalentnosti in teme našega prispevka je omembe vreden frazem plesati tako, kot kdo gode (žvižga, igra) oz. tudi njegova različica kakor se gode, tako se pleše, ki ima v slovaščini ustreznico v enoti tancuje, ako mu pískajú (hrajú) s pomenom 'poslušno izpolnjevati ukaze, brez odpora se podrediti'. Frazem iti rakom žvižgat in ribam (žabam) gost (sln.) oz. samo iti rakom žvižgat ali iti žabam gost nosi pomen 'biti zaman, brez uspeha; propasti; umreti, ubiti se'. Janez Keber (1998: 210-218; 2011: 788-789) piše o več okoliščinah, ki so pomembne za nastanek te enote, pri čemer je nedvomno dejstvo, da je v pomenu frazema zaobsežena nesmiselnost opisanega dejanja. Keber njegov nastanek povezuje z nekdanjim kaznovanjem z utopitvijo. Slovenščina pozna tudi glagolski frazem gosti (mrmrati) v brado s pomenom 'govoriti kaj sam zase, skrivoma'. Njegova slovaška ustreznica je stalna besedna zveza hundrat' si (mrmlat'si) popod fúzy.

V obeh jezikih najdemo tudi frazeme s sestavinami hudec: godec $\mathbf{1 3}$ in huslista: goslač. V slovaščini odražata nizek socialni status in negotove razmere muzikantov paremiji rybár, vtáčnik a hudec - traja žobráci in ked' poznáš jedného huslistu a jedného gajdoša, poznáš dvoch žobrákov, v slovenščini pa je to dejstvo eksplicitno izraženo v frazemu mlad godec, star berač. O značaju ljudskih godcev in o njihovi postranski dejavnosti, ko so na porokah v času med posameznimi skladbami svatom pripovedovali zgodbe in smešnice (pogosto tudi nespodobne), priča slovenska enota godec je gobec. Zahtevnost igranja na gosli in preneseno tudi pomen 'vsaka umetnost zahteva vajo' izraža slovenski frazeotekstem goslač veliko strun potrga, preden postane mojster, podobna misel pa je izražena v enoti kdor zna strune ubrati, more lahko igrati. O lenih dekletih pripoveduje hudomušni starejši slovenski ljudski pregovor: bolna je, delat ne more; godci zagodejo, plesat pa pojde.

\subsection{Frazemi s sestavino basa : bas}

Bas, v slovaščini basa, je pogovorni izraz za kontrabas, največji godalni inštrument $\mathrm{z}$ najglobljimi, nizkimi toni, ki se je razvil v drugi polovici 16. stoletja iz basove in kontrabasove viole da gamba (Laborecký 1997: 120). Na Slovaškem je bil neločljiv del ljudskih veselic, povezan pa je tudi z obredom pokopavanja

12 Pomensko sorodna je slovaška frazeološka enota ako obohratá platňa (opakovat', hovorit'), njena slovenska ustreznica pa je frazem kot 〈stara〉 lajna (govoriti, ponavljati).

13 Zavedamo se, da leksema hudec : godec označujeta človeka, ki igra ljudsko glasbilo na splošno, ne samo violinista (goslača), vendar smo se, izhajajoč iz navedenega pomena slovaškega glagola húst', torej ,igrati glasbeni inštrument (po navadi violino)“ (SSSJ 2011: 222), odločili navesti tudi frazeme s tema dvema sestavinama. 
basa,14 ki se je v velikem delu Slovaške odvijal na pustni torek pred pepelnično sredo (Nádaská 2012: 98).

Prav ta pogovorna sestavina basa je konstrukcijski element več slovaških frazemov. Na podobnosti oblike in dimenzij je osnovan primerjalni frazem tučná ako basa (sľs.), ki se uporablja, kot je razvidno iz same oblike enote, predvsem v povezavi z ženskami. V slovenščini se za debelo žensko uporablja slabšalno poimenovanje bajsa, moška oblika pa je bajs. Kot navaja Slovenski etimološki slovar (SES 1997: 22), je ta beseda tudi narečno poimenovanje za glasbilo kontrabas, zato je verjetno, da so leksemi bajs, bajsa metaforično izpeljani prav iz njega, motivacijska baza njihovega nastanka je torej podobna kot pri navedenem slovaškem frazemu. V zvezi s tem lahko omenimo še slovenski frazem z rimo s pomenom 'debela ženska’ bajsa debelajsa. Ekvivalentni frazeološki primerjavi tučný (bachratý) ako sud (slš.) : debel kot sod (brenta) (sln.), prav tako osnovani na zunanji podobnosti, se lahko nanašata na oba spola, leksem brenta (sln.) pa sam po sebi, podobno kot bajsa (sln.), slabšalno označuje debelo žensko.

Akustična podobnost pa je bila osnova za nastanek slovaškega frazeotekstema chrápe, akoby na base t'ahal. Sinonimna enota s podobno motivacijsko bazo je frazem chrápe, akoby drevo pílil (slš.). Slovenščina izraža identični pomen s frazemom z živalsko sestavino smrčati kot medved. Zvočna podoba sestavin basa in gajdy in negativne konotacije, ki so z njo včasih povezane, se zrcalijo tudi v ljudski grožnji starejšega izvora nech sa ti basy s gajdami odslúžia (slš.).

V slovaščini je pogost in razširjen frazem sprostý (hlúpy) ako basa s pomenom 'zelo neumen', sinonimni primerjalni frazem, kjer je sestavina tudi inštrument, pa je sprostý ako 〈pastierova〉 trúba (slš.). Za tertium comparationis teh primer lahko imamo »enostavnost« - v primeru glasbenih inštrumentov v obliki monotonosti igranja na kontrabas oz. omejenega obsega tonov pri igranju na trobento, v primeru človeka pa v obliki njegove duševne omejenosti, nedojemljivosti (Svítková 2015: 58). Hrvatsko-slavenski rječnik poredbenih frazema (Fink Arsovski 2006: 166) navaja kot njune slovenske ustreznice frazema neumen kot noč in zabit kot vol.

Pomembna vloga kontrabasa v ljudski glasbi, dejstvo, da daje in pomaga držati ritem, ki je obvezen tudi za druge inštrumente, se odraža v stavčnem pogovornem frazemu basa tvrdí muziku (slš.) s pomenom 'imeti odločujoč pomen'. V slovaščino je najbrž prešel iz češčine, podobno kot tudi naslednji pogovorni frazem, priljubljen zlasti v političnem diskurzu držat' basu 〈niekomu (s niekým)〉 (slš.), kar pomeni 'biti solidaren s kom, lojalen do koga, pomagati komu'.

Starejši primerjalni frazem z zgradbo stavka in s pomenom 'zelo dobro ga pozna' je pozná to $v$ ňom ako $v$ base trojník(slš.). Gre za odraz običaja z veselic, ko

14 Gre za ljudsko igro, ki je parodija na resnični pogreb, kjer se pokopava bas in s tem tudi plesi in zabave v času prihajajočega 40-dnevnega predvelikonočnega posta. Ta obred potrjuje nezamenljivo vlogo basa v ljudski glasbi. 
so ljudje pri izboru pesmi po lastni želji kot nagrado muzikantom metali kovance v kontrabas. Glede na zvok kovanca je znal kontrabasist uganiti njegovo vrednost. V Sloveniji se podobna navada odraža v starejšem frazemu dati denar v gosli. Slovar sodobnega slovaškega jezika (Slovník súčasného slovenského jazyka, SSSJ 2006: 235) navaja tudi frazem dostat' basu (slš.), ki pa je povezan z drugim pomenom leksema basa v slovaščini, in sicer ,pog. ekspr. prostor ali stavba za zapornike, zapor", in pomeni 'priti v zapor'.

V slovenščini nismo našli nobenega sintagmatskega frazema s sestavino bas, se pa ta pojavlja v frazeotekstemih več bas da, kot zvon vzame ali kar zvon vzame, pa bas pribuč $i$, kjer sta glasbena inštrumenta uporabljena v simbolnem pomenu zvon z zgoraj omenjeno signalizacijsko funkcijo tukaj tradicionalno označuje smrt, bas pa kot tradicionalna sestavina ljudskih godčevskih skupin označuje poročno glasbo oz. poroko.

\subsection{Frazemi s sestavino klavír : klavir}

Klavir je strunsko glasbilo s tipkami, $\mathrm{v}$ katerem ton nastane $\mathrm{z}$ udarcem kladivca na struno. Njegov zunanji del tvori lesen trup, na njegovi sprednji strani je tipkovnica s 85 ali 88 tipkami. Prva klavirska mehanika, v kateri kladivce razzveni strune, je bila izdelana na začetku 18. stoletja (Laborecký 1997: 116). Koncertni klavir je masivno glasbilo s trdnimi nogami, prav tukaj pa je mogoče iskati motivacijo za nastanek slovaškega primerjalnega frazema $\langle$ mat $\rangle$ nohy ako klavir, torej 'imeti debele noge'. Frazem z zgradbo glagolske sintagme chodit' niekam ako na klavir (slš.) pomeni 'pogosto kaj obiskovati, pogosto kam hoditi'. Njegova motivacija je lahko razumljiva: ker je učenje klavirja zelo zahtevno, morajo učenci redno in razmeroma pogosto obiskovati učne ure in veliko vaditi. Ta pogovorna enota je $\mathrm{v}$ jeziku živa in se pogosto uporablja.

Slovar slovenskih frazemov (Keber 2011: 341) navaja eno frazeološko enoto s sestavino klavir, in sicer frazem z zgradbo glagolske sintagme iti igrat klavir. Njegov pomen je 'iti v zapor odslužit kazen'. Motivacijo nastanka frazema je najbrž treba iskati v podobnosti pozicije rok pri igranju klavirja, pri čemer so roke lahko tudi prekrižane, ravno tako kot pri vklenitvi, ko so v lisicah. Frazem je uvrščen tudi v spletni prosti slovar žive slovenščine Razvezani jezik. Manjšalnica klavirček je sestavina ustaljenega poimenovanja znane slovenske otroške igre klavirčke prodajati.

\subsection{Frazemi s sestavino harfa}

Harfa, kordofon trikotne oblike s 43-47 strunami in sedmimi pedali, na katerega se brenka s prsti obeh rok, spada med najstarejše inštrumente. Iz Srednje Azije in Egipta se je začela širiti že v 3. tisočletju pr. n. š. (Laborecký 1997: 80). SSSJ (2011: 51) navaja kot drugi pomen leksema harfa: ,„labš. stara ženska (pogosto kot žaljivka)“. V slovaščini smo to sestavino našli v ustaljeni primeri rozumie $\langle s a\rangle$ tomu ako osol harfe $\langle$ a sliepka pivu $\rangle$. V vsakem jeziku verjetno obstajajo podobni 
ironični izrazi s pomenom 'sploh se ne spoznati na kaj', posamezni jeziki pa so si zanj našli svoja posebna sredstva. V slovenščini poznamo enote, ki prav tako za izražanje identičnega pomena uporabljajo kot sestavino glasbilo, in sicer boben. Gre za frazeme razumeti se (spoznati se) na kaj kot zajec na boben, biti toliko za kaj kolikor zajec za boben oz. tudi redkejši primerjalni frazem kakor krava na boben. Poleg glasbene imajo te enote skupno tudi živalsko sestavino, ki tu služi kot intenzifikator; ta zvišuje kontrast, s tem pa tudi ekspresivnost frazema. Navedeni frazemi imajo v obeh jezikih v sebi tudi implicitno zakodirano informacijo o tem, da je igra na glasbenem inštrumentu bila in je še vedno šteta za posebno vrlino, ki je ne obvlada vsak. V sodobnem slovaškem jeziku se najpogosteje uporablja frazem rozumiet'sa niečomu (do niečoho) ako hus do piva z enakim pomenom, redkeje pa se uporabljata njegovi frazeološki sinonimi rozumiet' sa niečomu (do niečoho) ako koza petržlenu (ako krava muškátu).

\subsection{Frazemi s sestavino citre}

Citara, v slovenščini citre, so ljudsko strunsko glasbilo iz družine brenkal, pravokotne ali trapezaste oblike, ki so bile v preteklosti razširjene po celi Slovaški (Laborecký 1997: 39), kjer pa so danes kot del ljudskega inštrumentarija skoraj nepoznane. Priljubljene so bile tudi v Sloveniji, in to predvsem v alpskih predelih, kjer so se ohranile do danes. 15 Enostavnejše citre so si ljudje izdelovali tudi doma in jih po domače imenovali švrkovence, drsovca, drskalca. Na citre so rade igrale tudi ženske (Kumer 1972: 45). V slovenskem paremiološkem fondu najdemo ljudsko modrost, da mora vsak delati to, kar zna in kar se zanj spodobi, to pa je izraženo v enoti za citrarja ni plug in za oratarja (orača, kmeta) ne citre. Omembe vredna je tudi besedna zveza kazati citre, ki jo v svojem etimološkem slovarju navaja France Bezlaj (1977: 163), s pomenom 'kazati prsi'. V primerjavi s prej omenjenim frazemom kazati gosli se je pa ta po Bezlaju uporabljal izključno v zvezi $\mathrm{z}$ žensko. Med slovaškimi frazemi nismo našli nobenega s sestavino citara, kar se ujema z dejstvom, da ta inštrument ni tradicionalni del ljudskega inštrumentarija.

\subsection{Frazemi s sestavino bendžo}

Bendžo je črnsko strunsko glasbilo iz družine brenkal s tamburinu podobnim trupom, prevlečenim $\mathrm{z}$ usnjem, $\mathrm{z}$ daljšim vratom in $\mathrm{s}$ štirimi do sedmimi kovinskimi strunami, na katere igramo s trzalico. V Evropo je prišel v dvajsetih letih 20. stoletja (Laborecký 1997: 23; Kurfürst 2002: 427). Kljub temu da se je leksem bendžo v slovaščini udomačil šele pred kratkim, 16 o čemer priča tudi to, da se je še pred nedavnim beseda pisala kot banjo, najdemo v frazeološkem fondu slovaškega jezika protipomensko glagolsko pogovorno dvojico z visoko

15 Razlika v razširjenosti citer na Slovaškem in v Sloveniji je že na prvi pogled očitna tudi iz korpusov, kajti v SNK smo pri leksemu citara našli 10 zadetkov, v korpusu Gigafida za citre več kot tri tisoč, približno 1300 zadetkov ima tudi leksem citrar. 
stopnjo ekspresivnosti dat' niekomu na bendžo in dostat' na bendžo. Frazema nosita pomen 'pretepsti koga' in 'biti pretepen'. Motivacija nastanka ni povsem jasna, metaforničnost frazema pa morda temelji na podobnosti med okroglo obliko bendža z resonančno odprtino in človeško glavo z usti. V prenesenem pomenu 'premagati koga' ali 'biti poražen' se frazema uporabljata na primer v povezavi s športom, npr.:

Ešte pred necelými štrnástimi mesiacmi o nás písali, že sme to najmizernejšie mužstvo na svete a odporúčali nám, aby sme radšej hrali pigu ako futbal. Dobre, ked' chcú dostat' na bendžo, nie sme proti zohratiu priatel'ského zápasu s nimi. (slš.) (Vir: SNK 17)

V slovenščini obstaja za omenjeni glasbeni inštrument poimenovanje bendžo oz. banjo, nismo pa našli nobenega frazema s to sestavino.

\subsection{Frazemi s sestavino struna}

V primeru besede struna, ki se v enaki obliki uporablja v slovaščini in slovenščini, ne gre za poimenovanje glasbila, temveč njegovega sestavnega dela. Ker pa je ta leksem v zvezi s frazeologijo zelo produktiven, smo se ga odločili uvrstiti v prispevek. Več slovenskih frazemov v tej skupini je pomensko povezanih z drugim pomenom leksema struna, ki je naveden v SSKJ, torej knjiž., ekspr., s prilastkom ,lastnost, značilnost koga glede na odzivanje na zunanje dogodke“, na primer brenkati na čustvene strune 'skušati vplivati na čustva; govoriti čustveno'. Slovaška ustreznica je frazem udierat' (brnkat') niekomu na 〈citlivú〉 strunu.

Po svoji zgradbi, ne pa po pomenu, sta predhodnemu podobna slovenska frazema ubrati smešno struno 'pošaliti se, povedati kaj smešnega' in zadeti pravo struno 'najti pravi način'. Slovaška ustreznica slednjega je udriet' (trafit') niekomu na pravú strunu. Popolni ustreznici napeti drugačne strune ( $\sin$.) in natiahnut' inú (inakšiu) strunu (sľ̌.) nosita pomen 'lotiti se stvari na drugačen način, bolj strogo'. Identično miselno vsebino oz. celo grožnjo izraža slovaški frazeotekstem s tebou musím iné struny natiahnut'. Slovenski frazem $v$ svojih zahtevah je prenapel strune se uporablja v pomenu 'preveč je zahteval', frazeološke enote $\mathrm{z}$ istim pomenom in sestavo pa slovaščina ne pozna.

Slovaška frazeološka enota, ki temelji na zunanji podobnosti oblike (lastnosti), je primera byt'〈rovný (pružný) $\rangle$ ako struna. SSKJ navaja v ilustrativnem gradivu leksema struna zvezo cesta, ravna kot struna, ki pa ni uvrščena v frazeološko gnezdo, tako da v tem primeru (sodeč tudi po rezultatih iskanja v korpusu Gigafida) verjetno ne gre za frazem. V slovenščini pa se pogosto uporablja frazeološka primera, ki ne govori o fizični lastnosti, temveč o psihičnem stanju denotata: biti napet kot struna 'biti zelo napet'.

Slovar slovaškega jezika (Slovník slovenského jazyka, SSJ 1: 308) iz leta 1959 navaja tudi starejše frazeme, ki so jih postopoma nadomestili frazeološki

17 http://korpus.juls.savba.sk:8080/manatee.ks/do_query?query=dosta $\% \mathrm{C} 5 \% \mathrm{~A} 5 \% 20 \mathrm{na} \% 20$ bend $\%$ C5\%BEo\&corpname $=$ prim- 6.0 -public -all\&start $=0 \& \mathrm{cnt}=10$ 
sinonimi, so pa zanimivi z vidika teme prispevka, in sicer chodit' ako na strunách 'biti v napetem pričakovanju, duševnem stanju', žilky $v$ ňom hrali ako struny 'bil je nestrpen' in šlo mu to ako po strune 'stvar je potekala gladko, dobro'. Sestavina struna se pojavlja tudi v paremioloških enotah. Potrebo poznati pravo mero vsega so tako Slovaki kot Slovenci izrazili v pregovorih strunu dotial' nat'ahujú, kým nepraskne (slš.) in prenapeta struna poči ( $\operatorname{sln}$.). V slovenščini smo zabeležili tudi pregovor ko struna najbolje poje, se rada utrga. Enotnost dejanja dveh ali več ljudi je izražena v slovaški paremiji na jednu strunu bijú (drnkajú).

\section{ZAKLJUČEK}

Vokalni, glasbeni in plesni izrazi so že od nekdaj naravni del človeškega življenja. Izhajajo iz samega bistva človeka, zato so se na različne načine, tudi v podobi frazeoloških enot, projicirali v njegovo konceptualizacijo sveta. Frazemi, ki obsegajo poimenovanja glasbenih inštrumentov, in tudi leksemi, pomensko povezani $\mathrm{z}$ igranjem nanje, s petjem ali plesom, tvorijo nezanemarljiv del frazeološkega fonda slovaškega in slovenskega jezika. Nekatere posebnosti ljudskih glasbenih inštrumentarijev so se pokazale $\mathrm{v}$ frazeologiji obeh jezikov v podobi obstoja ali neobstoja frazemov, ki kot eno izmed komponent vsebujejo dane glasbene inštrumente (npr. dude ali citre). Splošna razširjenost in priljubljenost violine v ljudski kulturi se je odzrcalila v relativno velikem številu enot, katerih sestavni del je. Frazeme smo črpali iz dostopnih slovaških in slovenskih virov, predvidevamo pa, da mnoge izmed njih, predvsem narečne enote, v njih niso zajete, zato pa bi bila za njihov celosten prikaz potrebna terenska raziskava. Nekatere enote kažejo na nizek socialni in ekonomski status glasbenikov v preteklosti, kljub temu da je igranje na glasbene inštrumente bilo in je posebna vrlina, ki je ne obvlada vsak. Zanimivi so frazemi, v katerih se naenkrat pojavljajo glasbene in živalske sestavine, s čimer se stopnjuje ekspresivnost ustaljenih zvez. Z analizo frazeološke teme, ki zadeva glasbeno področje, smo želeli prispevati k raziskavi dane problematike v okviru slovaške in slovenske primerjalne frazeologije ter tako dopolniti manjkajoči del mozaika slovanske jezikovne slike sveta.

Prevedla Darija Pivk

\section{LITERATURA IN VIRI}

Bezlaj 1977 = France Bezlaj, Etimološki slovar slovenskega jezika 1: A-J, Ljubljana: Mladinska knjiga, 1977.

Dobríková 2010 = Mária Dobríková, Gajdošské motívy v slovenskej a bulharskej frazeológii, v: Phraseologische Studien: dynamische Tendenzen in der slawischen Phraseologie, ur. Dana Baláková - Harry Walter, Greifswald: Institut für Fremdsprachliche Philologien - Slawistik, 2010, 113-120.

Dobríková 2014 = Mária Dobríková, Ouvertúra alebo Slovo na úvod, v: Frazeologické štúdie VI: hudobné motívy vo frazeológii, ur. Mária Dobríková, Bratislava: Univerzita Komenského, 2014, 9-10. 
Dobríková 2015 = Mária Dobríková, Signalling Function of Musical Instruments from the Aspect of Ethnophraseology, Езиков свят - Orbis linguarum 13 (2015) št. 2, 7-15.

Dobríková 2016 = Mária Dobríková, Signálne hudobné nástroje ako motivanty frazém v slovenčine, v: Studia Academica Slovaca 45, ur. Jana Pekarovičová - Miloslav Vojtech, Bratislava: Univerzita Komenského, 2016, 418-435.

Fink Arsovski 2006 = Željka Fink Arsovski idr., Hrvatsko-slavenski rječnik poredbenih frazema, Zagreb: Knjigra, 2006.

Gigafida = Korpus slovenskega jezika Gigafida $\langle$ http://www.gigafida.net, dostop 6. 10. 2016.

Glasba 6 = Glasba 6: delovni zvezek za šesti razred devetletne osnovne šole, ur. Marjeta Pušenjak, Ljubljana: Mladinska knjiga, 2004.

Habovštiaková - Krošláková 1996 = Katarína Habovštiaková - Ema Krošláková, Frazeologický slovník: človek a príroda vo frazeológii, Bratislava: VEDA, vydavatel'stvo SAV, 1996.

Jež - Lipovšek 1989 = Jakob Jež - Marijan Lipovšek, Pregled in opis glasbil, Ljubljana: Državna založba Slovenije, 1989.

Keber 1998 = Janez Keber, Živali v prispodobah 2, Celje: Mohorjeva družba, 1998.

Keber 2011 = Janez Keber, Slovar slovenskih frazemov, Ljubljana: Založba ZRC, ZRC SAZU, 2011 (Slovarji).

Kocbek 1887 = Fran Kocbek, Pregovori, prilike in reki, Ljubljana: Anton Trstenjak, 1887.

Kocbek - Šašelj 1934 = Fran Kocbek - Ivan Šašelj, Slovenski pregovori, reki in prilike, Celje: Družba sv. Mohorja, 1934.

Kovačič 2015 = Mojca Kovačič, V deželi harmonike - nacionalizacija harmonike v slovenskem kontekstu, v: Venček domačih: predmeti, Slovencem sveti, ur. Jernej Mlekuž, Ljubljana: Založba ZRC, ZRC SAZU, 2015.

Kržišnik 2014 = Erika Kržišnik, Glas in glasba v slovenski frazeologiji, v: Frazeologické štúdie VI: hudobné motívy vo frazeológii, ur. Mária Dobríková, Bratislava: Univerzita Komenského, 2014, 191-201.

KSSJ = Krátky slovník slovenského jazyka, ur. Ján Kačala - Mária Pisárčíková, Bratislava: VEDA, vydavatel'stvo SAV, 2003.

Kumer 1972 = Zmaga Kumer, Slovenska ljudska glasbila in godci, Maribor: Obzorja, 1972.

Kumer 1983 = Zmaga Kumer, Ljudska glasbila in godci na Slovenskem, Ljubljana: Slovenska matica, 1983.

Kurfürst 2002 = Pavel Kufürst, Hudebni nástroje, Praha: TOGGA, 2002.

Laborecký 1997 = Jozef Laborecký, Hudobný terminologický slovník, Bratislava: Slovenské pedagogické nakladatel'stvo, 1997.

Leng 1967 = Ladislav Leng, Slovenské l'udové hudobné nástroje, Bratislava: Vydavatel'stvo slovenskej akadémie vied, 1967.

Mačák 1995 = Ivan Mačák, Dedičstvo hudobných nástrojov, Bratislava: Slovenské národné múzeum - hudobné múzeum, 1995.

Mlacek 1984 = Jozef Mlacek, Slovenská frazeológia, Bratislava: Slovenské pedagogické nakladatel'stvo, 1984.

Mlacek - Ďurčo 1995 = Jozef Mlacek - Peter Duurčo idr., Frazeologická terminológia, Bratislava: Stimul, 1995.

Mokijenko 2014 = Валерий Мокиенко, Первая скрипка музыкальной фразеологии, v: Frazeologické štúdie VI: hudobné motívy vo frazeológii, ur. Mária Dobríková, Bratislava: Univerzita Komenského, 2014, 15-31.

Nádaská 2012 = Katarína Nádaská, Slovenský rok v l’udových zvykoch, obradoch a sviatkoch, Bratislava: Fortuna Libri, 2012.

Prek 1972 = Stanko Prek, Ljudska modrost trden je most, Maribor: Obzorja, 1972.

Razvezani jezik = Razvezani jezik: prosti slovar žive slovenščine $\langle\mathrm{http}: / /$ razvezanijezik.org/?page= iti+igrat+klavir, dostop 6. 10. 2016).

SES 1997 = Marko Snoj, Slovenski etimološki slovar, Ljubljana: Mladinska knjiga, 1997.

SESS 2015 = Lubor Králik, Stručný slovník slovenského jazyka, Bratislava: VEDA, vydavatel'stvo SAV - Jazykovedný ústav Ludovíta Štúra SAV, 2015. 
Smiešková 1988 = Elena Smiešková, Malý frazeologický slovník, Bratislava: Slovenské pedagogické nakladatel'stvo, 1988.

SNK = Slovenský národný korpus - prim-7.0-public-all 〈http://korpus.juls.savba.sk, dostop 6. 10. 2016).

SSJ = Slovnik slovenského jazyka 1-6, ur. Štefan Peciar, Bratislava: Vydavatel'stvo Slovenskej akadémie vied, 1959-1968.

SSKJ = Slovar slovenskega knjižnega jezika, Ljubljana: DZS, 1994.

SSSJ 2006 = Slovník súčasného slovenského jazyka: $A-G$, ur. Klára Buzássyová - Alexandra Jarošová, Bratislava: VEDA, vydavatel'stvo SAV, 2006.

SSSJ 2011 = Slovník súčasného slovenského jazyka: $H-L$, ur. Alexandra Jarošová - Klára Buzássyová, Bratislava: VEDA, vydavatel'stvo SAV, 2011.

Stramljič Breznik 2015 = Irena Stramljič Breznik, Kolektivna monografija o glasbenih motivih v frazeologiji, Jezikoslovni zapiski 21 (2015), št. 1, 177-181. - Ocena.

Svítková 2015 = Milina Svítková, Hudobné nástroje ako komponenty slovenských a chorvátskych frazém, dizertačná práca, Univerzita Komenského v Bratislave, Bratislava: [M. Svítková], 2015. - Razmnoženo.

Záturecký 2005 = Adolf Peter Záturecký, Slovenské prislovia, porekadlá, úslovia a hádanky, Bratislava: Slovenský Tatran, 2005.

Zbirka pregovorov Inštituta za slovensko narodopisje ZRC SAZU, Ljubljana.

\section{SUMMARY}

\section{Expressions for Chordophone Instruments in Slovak and Slovenian Phrasemes}

Vocal and instrumental music and dance have always been a natural part of people's lives. They stem from human nature, and therefore they are naturally reflected in conceptualization of the world, and also in phraseological units. Phrasemes containing the names of musical instruments and lexemes related to playing them, singing, or dancing form a significant part of the phraseological corpus of Slovak and Slovenian. Some special features of folk musical instruments have entered the phraseology of both languages through phrasemes that contain individual instruments as components (e.g., the bagpipes or zither). The fact that the violin is widely used and popular in folk culture is shown in the many units that include it as a component. The phrasemes were obtained from a variety of Slovak and Slovenian sources; however, it is likely that many of those existing in dialects may have not been included, and therefore it is suggested that field research should be carried out in order to achieve a complex mapping. Some units speak of the low socioeconomic status of folk musicians in the past despite the fact that being able to play a musical instrument was regarded as a special skill not possessed by just anybody. Notable are also phrasemes featuring instrumental and zoonymic components, which make the set expressions even more expressive. The analysis of phraseological themes overlapping with music contributes to research on comparative phraseology in Slovak and Slovenian and adds to the body of knowledge about Slavic languages' conceptualization of the world. 